\title{
Uebersicht des Inhalts.
}

I. Das Receptaculum. Entstehungsfolge der Blüthen. Bckleidung des Receptaculum . . . . . . . . . . . 2

2. Bildung der Blüthe.

Die ersten Entwickelungstadien. . . . . . . . . 18

Entstehungsfolge der Blüthentheile. . . . . . . . . 20

Krone . . . . . . . . . . . . . . . . 20

Androeceum . . . . . . . . . . . . . . 24

Gynoeceum . . . . . . . . . . . . . . . 26

Nectarium . . . . . . . . . . . . . . . . 27

Kelch. Becherförmige Achsenaushöhlung . . . . . . 28

Histologie des Kelchwulstes . . . . . . . . . 36

Bildung des Pappus. . . . . . . . . . . . . 37

Allgemeine Scblüsse über das Wachsthum des Pappus . . . 61

Gemeinsamer Wachsthumsmodus der Glieder bei den Angiospermen . . . . . . . . . . . . . . . . 66

Laterale Bildungen der Pappus-Körper und andere Metablasteme der Compositen . . . . . . . . 73

Definition von Trichomen (Metablastemen) . . . . 77

3. Zahl und Stellung der Pappus-Körper $\quad$. . . . . . . . . . . . . $\quad$. 79

Gattungen vom Bidens-Typus . . . . . . . . . . 80

, D Cirsium-Tragopogon-'Typus . . . . . . 90

, , Senecio-Lactuca-Typus . . . . . . . . 96

, Centaurea-Typus . . . . . . . . . 100

Allgemeine Schlüsse. Bedeutung des Drucks der umgebenden alteren Theile . . . . . . . . . . . . . . . 101

Anhang. Beobachtungen über Valerianaceen und Dipsaceen . 108 
Seite

4. Der morphologische Werth der Kelchtheile . . . . . . . . . 109

Der Kelchwulst und seine Ecken . . . . . . . . 111

Entwickelungsgeschichte von Acicarpha spathulata . . . . 112

Verspätung von Gliedern . . . . . . . . . . . 113

Morphologischer Werth des Pappus. . . . . . . 118

a) Seine Entstehung im Allgemeinen. Entstehungsfolge . 120

b) Die Stellungsverhältnisse . . . . . . . . . . . 123

c) Bau und anatomische Entwickelung . . . . . . . 127

d) Bildungsabweichungen. Neue Beobachtungen von Dr. Köhne . . . . . . . . . . . . . . 130

e) Vergleichung der Compositen unter sich und mit verwandten Familien . . . . . . . . . . . . . . 141

Abschliessende Uebersicht . . . . . . . . . . . . . . . 147 